\title{
Three transcripts of EDS1-like genes respond differently to Vitis flexuosa infection
}

\author{
Md. Zaherul Islam • Hae Keun Yun
}

Received: 31 May 2017 / Revised: 2 June 2017 / Accepted: 16 June 2017

(C) Korean Society for Plant Biotechnology

\begin{abstract}
Enhanced disease susceptibility1 (EDS1) is a regulator of basal defense responses required for resistance mediated by TIR-NBS-LRR containing R proteins. We identified three transcripts of EDS1-like genes encompassing diverse/ separate expression patterns, based on the transcriptome analysis by Next Generation Sequencing (NGS) of $V$. flexuosa inoculated with Elsinoe ampelina. These genes were designated VfEDL1 (Vitisflexuosa Enhanced Disease Susceptibility1-like1), VfEDL2 and VfEDL3, and contained 2464, 1719 and 1599 bp, with 1791, 1227 and 1599 bp open reading frames (ORFs), encoding proteins of 596, 408 and 532 amino acids, respectively. The predicted amino acid sequences of all three genes showed the L-family lipase-like domain (class 3 lipase domain), and exhibited a potential lipase catalytic triad, aspartic acid, histidine and serine in the conserved G-X-S-X-G. All three VfEDL genes were upregulated at $1 \mathrm{hpi}$ against the bacterial and fungal pathogens Rizhobium vitis and E. ampelina, respectively, except VfEDL1, which was downregulated against E. ampelina at all time points. Against E. ampelina, VfEDL2 and VfEDL3 showed downregulated expression at later time points. When evaluated against $R$. vitis, VfEDL1 showed downregulated expression at all time points after $1 \mathrm{hpi}$, while $V f E D L 3$ showed upregulation up to $24 \mathrm{hpi}$. Based on the expression response, all three genes may be involved in plant resistant responses against $R$. vitis, and $V F E D L 2$ and $V F E D L 3$ show additional resistant responses against E. ampelina infection.
\end{abstract}

Keywords Disease resistance, Elsinoe ampelina, Enhanced disease susceptibilityl, Hypersensitive response, Rhizobium vitis

\section{Md. Z. Islam}

On-Farm Research Division, Bangladesh Agricultural Research Institute, Pabna 6600, Bangladesh

H. K. Yun $(\bowtie)$

Department of Horticulture and Life Science, Yeungnam University, Gyeonsan 38541, Korea

e-mail: haekeun@ynu.ac.kr

\section{Introduction}

Plants constantly encounter various pathogens and have therefore evolved several defense mechanisms to protect themselves from attacks by pathogens. Resistance (R) and defense related genes are involved in resistance reactions in plants, and the $\mathrm{R}$ gene is necessary for them to recognize pathogen attacks (Hammond-Kosack and Jones 1996). The genetic interaction between an $\mathrm{R}$ gene and an Avr gene drives activation of plant disease resistance signaling cascades, resulting in the induction of defense gene expressions, hypersensitive response (HR) and elicitation of systemic acquired resistance (Staskawicz et al. 1995; Hammond-Kosack and Jones 1996; Dangl and Jones 2001).

Disease resistance $(\mathrm{R})$ genes are believed to confer resistance to specific diseases caused by fungi, bacteria, viruses, oomycetes or nematodes (Taler et al. 2004). A major class of $\mathrm{R}$ genes encodes the nucleotide binding site-leucine rich repeat (NBS-LRR) (Joshi and Nayak 2011). Based on the N-terminal motif, NBS-LRR class R genes are classified into two major classes, TIR-NBS-LRR (TNL), which contains a Toll Interleukin-1 receptors (TIR) motif in the N-terminal, and CC-NBS-LRR (CNL), which contains a coiled-coil (CC) or a leucine-zipper (LZ) motif in the N-terminal (Meyers et al. 1999; Pan et al. 2000; Liu et al. 2007; Joshi and Nayak 2011). In addition to $\mathrm{R}$ genes, mutational analysis in Arabidopsis revealed several genes required for the $\mathrm{R}$ gene mediated resistance and signaling pathway, including EDS1, NDR1, PAD4, SID1, EDS5, SID2, EDS16, NPR1 and NIMI (Cao et al. 1994; Century et al. 1995; Delaney et al. 1995; Glazebrook et al. 1997; Rogers \& Ausbel 1997; Aarts et al. 1998; Zhou et al. 1998; Falk et al. 1999; Nawrath and Metraux 1999; Rusterucci et al. 2001). EDS1 and NDR1 are required for resistance mediated by several $\mathrm{R}$ genes encoding TIR-NBS-LRR and CC/LZ-NBS-LRR proteins, respectively (Century et al. 1995; Aarts et al. 1998; Falk et al. 1999; Rusterucci et al. 2001). EDS1 is also required for 
basal resistance in plants (Wanger et al. 2013). EDS1 nuclear accumulation is necessary for transcriptional defense reprogramming in both effector-triggered immunity (ETI) and basal immunity (Garcia et al., 2010; Heidrich et al., 2011). $E D S 1$ encodes lipase-like protein, which functions upstream of salicylic acid (SA)-dependent PR1 mRNA accumulation against an avirulent bacterial pathogen in Arabidopsis (Falk et al. 1999).

Cultivated grapevines (Vitis spp.) are exposed to many pathogenic fungi, bacteria, and viruses (Wang et al. 2011). Grape anthracnose caused by fungal pathogenic E. ampelina (Yun et al. 2007; Kono et al. 2009) and crown gall caused by bacterial pathogenic $R$. vitis (Eastwell et al. 2006) are major devastating diseases that result in loss of yield and quality of grapes. The use of commercial fungicides to control diseases is very expensive and causes various adverse impacts on the environment; therefore, interest in development of resistant varieties is increasing.

Several signaling regulators, including EDS1, NDR1, PAD4, SID1, EDS5, SID2, EDS16, NPR1 and NIM1, have been characterized and shown to play roles in signaling cascades in pathways to pathogen resistance in plants. Although cultivated grapevines ( $V$. vinifera $\mathrm{L}$.) are highly susceptible to several diseases, some wild cultivars such as $V$. riparia, $V$. rupestris, $V$. rotundifolia and $V$. flexuosa are reportedly resistant to several important grapevine diseases (Eibach et al. 1989; Kortekamp et al. 2008; Ahn et al. 2012). In a previous study, we found several transcripts of EDS1like genes with differential expression levels in the transcriptome of $V$. flexuosa infected with E. ampelina (Ahn et al. 2014). Therefore, in this study, we cloned three EDS1-like genes in $V$. flexuosa to characterize these genes by analyzing their structural features and phylogenetic relationship with other plants, and by investigating their expression patterns in response to infection by $E$. ampelina and $R$. vitis.

\section{Materials and Methods}

Plant materials and pathogens

$V$. flexuosa VISKO001 plants were cultured in pots at the green house of Horticulture and Life Science in Yeungnam University, Gyeongsan, Korea, for leaf production. Leaves were used for gene expression analysis following pathogen inoculation. The pathogens used in this study were virulent strains of E. ampelina (EA-1) and B. cinerea (B1035) that were isolated from infected grapes by Dr. W.K. Kim, National Academy of Agricultural Science, Rural Development Admin- istration, Korea and $R$. vitis strain Cheonan 493, which was kindly provided by Prof. J.S. Cha, Chungbuk National University, Korea.

Inoculation of pathogens

Spores of E. ampelina were produced according to Yun et al. (2007), then collected by scraping off of the plates with sterile distilled water. The concentrations of the spore suspensions were measured using a hemocytometer and adjusted to $10^{6}$ spores $\mathrm{mL}^{-1}$. Inoculation of spore suspensions was performed by spraying onto leaves. After growing single colonies of $R$. vitis on potato dextrose agar (PDA), a single colony was transferred to YEP medium (yeast extract $10 \mathrm{~g}$, bacto peptone $5 \mathrm{~g}, \mathrm{NaCl} 5 \mathrm{~g} \mathrm{~L}^{-1}$ and $\mathrm{pH}$ 7.0) and grown at $28^{\circ} \mathrm{C}$ in a shaking incubator for 16 to 18 hours. The bacterial cells were subsequently collected by centrifugation and resuspended in sterile water at a concentration of $\mathrm{OD}_{600}$ $=1$. Next, the leaves were injured slightly with a pencil tip and inoculated by dropping $20 \mu \mathrm{L}$ of $R$. vitis cell suspensions onto the wounded portion of the leaves. Leaves inoculated with spore suspensions were subsequently incubated in a moist box at $22-28^{\circ} \mathrm{C}$ for $48 \mathrm{~h}$. Leaves were harvested at $0,1,6,12,24$, and 48 hours post inoculation (hpi).

\section{Isolation of total RNA and first-strand cDNA synthesis}

Leaf samples were ground in liquid nitrogen using a mortar and pestle, after which total RNA was extracted using the modified pine tree method described by Chang et al. (1993). The RNA quality was then measured based on the absorbance at 230, 260 and $280 \mathrm{~nm}$ using a Nano Drop spectrophotometer (ACTGene ASP-3700; ACTGene, Inc., Piscataway, New Jersey, USA). Next, first-strand cDNA was synthesized from the total RNA (500 ng) using a GoScriptTM Reverse Transcription System (Promega, Madison, WI, USA).

Analysis of $V f E D L 2$ and $V f E D L 3$ through sequencing

PCR amplification of the VfEDL2 and VfEDL3 genes was conducted using cDNA and gene specific primers (forward: ATGGAAGCCCACGATTGCACTG; reverse: CTAATGG ATGAGTTTCATAATGCG and forward: GGCTTCCCAA TGATTAGTGTGC; reverse: TTACCCACCGATGAGTTTCGAA, respectively). The PCR conditions were as follows: $94^{\circ} \mathrm{C}$ for 5 minutes followed by 35 cycles of denaturation at $94^{\circ} \mathrm{C}$ for 45 seconds, annealing at $55^{\circ} \mathrm{C}$ for 45 seconds and extension at $72^{\circ} \mathrm{C}$ for 1 minute, with a final extension at 
Table 1 Specific primers based on alignment of the three VfEDL genes used for real time PCR

\begin{tabular}{ccl}
\hline Gene & Primers & \multicolumn{1}{c}{ Sequences } \\
\hline \multirow{2}{*}{$V f E D L 1$} & FP & CACGCTGAGTCTTCGTCAACCT \\
& RP & GAAAGGCAGAAGGGGAAGAGGG \\
FfEDL2 & FP & TAGCAAGAAACTGGGCTTACCC \\
& RP & CGTCATCGCCTAAACTTTTAAGCG \\
FPEDL3 & RP & ATATGGTGGAAAGGCCTTCGTCCC \\
& CCGATGAGTTTCGAAATGAAAG \\
\hline
\end{tabular}

FP: forward primer, RP: reverse primer

$72^{\circ} \mathrm{C}$ for 7 minutes. Following PCR, samples were electrophoresed on a $1 \%$ agarose gel and photographed using Benchtop UV Transilluminator gel doc (Cambridge, UK). Gel purified samples were either subjected to cloning using a TA cloning kit (RBC Bioscience, New Taipei, Taiwan) or sequenced directly by $\mathrm{ABI}$ sequencing (Xenotech, Daejeon, Republic of Korea).

\section{Real-time quantitative PCR analysis}

First-strand cDNA was subsequently used as a template for PCR. Real-time PCR was performed on a C1000TM Thermal Cycler (CFX96TM Real-Time System, BioRad, CA, USA) using SYBR Premix Ex Taq (TaKaRa Bio Inc., Osaka, Japan) as the fluorescent dye. Amplification was conducted by subjecting the samples to $95^{\circ} \mathrm{C}$ for $30 \mathrm{~s}$, followed by 40 cycles of $95^{\circ} \mathrm{C}$ for $5 \mathrm{~s}$ and $60^{\circ} \mathrm{C}$ for $30 \mathrm{~s}$. Transcript levels were calculated using the standard-curve method and normalized against the grapevine actin gene (AB372563) as an internal control and non-treated leaves (at time zero) as a reference. Melting curves of the amplified products were also recorded. For each gene, the reference sample was defined as the $1 \times$ expression level and the results were expressed as the fold increase in mRNA level over the reference sample. All reactions were performed in triplicate to minimize the experimental error. The specific primers used for real-time PCR are listed in Table 1.

Sequence analysis of genes

The nucleotide sequences of genes were converted to amino acid sequences using translation software (http://web.expasy. org/translate/) (Gasteiger et al. 2003). Analysis of primary structures of the genes was performed using ExPasy protParam (http://web.expasy.org/protparam/) (Gasteiger et al. 2003), while the secondary structure was analyzed using the SelfOptimized Prediction Method with Alignment (SOPMA) (https://npsa-prabi.ibcp.fr/cgi-bin/npsa_automat.pl?page=np sa _sopma.html) (Geourjon \& Deleage 1995). To verify the presence of the lipase 3 domain, the VfEDL protein sequences were analyzed using the web tool, Simple Modular Architecture Research Tool program (SMART) (http://smart.emblheidelberg.de/smart/set_mode.cgi?GENOMIC=1) (Letunic et al. 2009). Signal peptide searches were conducted with the SignalP 4.1 Server (http://www.cbs.dtu.dk/services/SignalP/), while the transmembrane helix region was searched using the TMHMM Server v. 2.0 (http://www.cbs.dtu.dk/services/ TMHMM/). Homologue protein sequences of the genes were searched by a BLAST (Basic Local Alignment Search Tool) of the NCBI database (http://blast.ncbi.nlm.nih.gov/ Blast.cgi) using the BLASTp tool and the "nr" database. The VfEDL proteins were blasted against each other to check for gene duplication events using NCBI blast (http://blast.ncbi.nlm.nih.gov/Blast.cgi). Multiple alignments of protein sequences were performed using ClustalW (http:// www.genome.jp/tools/clustalw/). Phylogenetic neighbor-joining analyses of gene sequences were performed using the Molecular Evolutionary Genetics Analysis (MEGA) version 6.0 software. The tree branches were evaluated using the bootstrap method.

\section{Results and Discussion}

Identification and sequence analysis of three EDL genes in V. flexuosa

Transcriptome analysis using NGS of $V$. flexuosa with an inoculation of E. ampelina (Ahn et al. 2014) revealed the presence of three different transcripts for EDS1-like genes. The transcripts for EDS1-like genes were verified for the presence of lipase 3 domain using the Simple Modular Architecture Research Tool (SMART) (http://smart.emblheidelberg.de/smart/set_mode.cgi?GENOMIC=1). One of these genes had the full coding sequence (CDS) with the characteristic lipase 3 domain, while the remaining two were 
Table 2 Predicted primary structure of three VfEDL genes of $V$. flexuosa

\begin{tabular}{|c|c|c|c|c|c|c|}
\hline Gene & $\begin{array}{l}\text { Nucleotide length } \\
\text { (bp) }\end{array}$ & $\begin{array}{l}{ }^{\mathrm{a}} \mathrm{ORF} \\
\text { (bp) }\end{array}$ & $\begin{array}{c}\text { Protein } \\
\text { length }(\mathrm{aa})\end{array}$ & $\begin{array}{l}{ }^{\mathrm{b}} \mathrm{MW} \\
(\mathrm{kDa})\end{array}$ & ${ }^{\mathrm{c}} \mathrm{pI}$ & $\begin{array}{l}\text { Instability } \\
\text { index (II) }\end{array}$ \\
\hline VfEDL1 & 2464 & 1791 & 596 & 68333.6 & 6.35 & 48.80 \\
\hline VfEDL2 & 1719 & 1227 & 408 & 46156.4 & 6.12 & 47.99 \\
\hline VfEDL3 & 1599 & 1599 & 532 & 60905.8 & 8.71 & 49.66 \\
\hline
\end{tabular}

${ }^{\mathrm{a} O R F}$ : open reading frame; ${ }^{\mathrm{b}} \mathrm{MW}$ : molecular weight; ${ }^{\mathrm{c}} \mathrm{pI}$ : isoelectric point

Table 3 Predicted secondary structures of three proteins determined from the EDL genes of $V$. flexuosa

\begin{tabular}{ccccc}
\hline Protein & Random coil & Alpha helix & Beta turn & Extended strand \\
\hline VfEDL1 & $28.36 \%$ & $48.99 \%$ & $8.05 \%$ & $14.60 \%$ \\
VfEDL2 & $26.23 \%$ & $51.23 \%$ & $8.33 \%$ & $14.22 \%$ \\
VfEDL3 & $30.26 \%$ & $53.38 \%$ & $5.45 \%$ & $10.90 \%$ \\
\hline
\end{tabular}

cloned for the full length coding sequence and characteristic lipase 3 domain. All genes showed the most similarity with AtEDS1 by their first hit, and were characterized and referred to as VfEDL1 (V. flexuosa Enhanced Disease Susceptibilityl like1), VfEDL2 and VfEDL3. The sequences were deposited in the National Agricultural Biotechnology Information Center (NABIC), Rural Development Administration, Korea under accession numbers NS-0829-000001, NS-0832-000001 and NS-0833-000001, respectively. The primary structure and the characteristics of VfEDL genes were analyzed using the bioinformatic tool, protParam (http:// web.expasy.org/protparam/), and the results are presented in Table 2. The results showed that the size of the VfEDL genes ranged from 1599 to 2464 base pairs (bp), while the open reading frame varied from 1227 to 1791 , encoding 408 to 596 amino acids. The molecular weight of VfEDL proteins ranged from 46.15 to $68.33 \mathrm{kDa}$, while the predicted isoelectric points varied from basic (6.12) to alkaline (8.71). All predicted proteins of VfEDL genes showed instability, with values of 48.88 to 49.66 in the instability index (II) proposed by Guruprasad et al. (1990) (Table 2). The secondary structures of the proteins predicted from the VfEDL genes were analyzed by SOPMA (Table 3 ). The results showed that random coil, alpha helix, beta turn and extended strands varied from 28.36 to $30.26 \%, 48.99$ to $53.38 \%, 5.45$ to $8.33 \%$ and 10.90 to $14.60 \%$ in amino acids, respectively. The prediction suggested that alpha helices are abundant structural elements of the VfEDL gene that are common features of other EDS1 genes. No predicted signal peptides or obvious transmembrane regions were detected by the SignalP 4.1 Server and TMHMM Server v. 2.0, which suggests that these proteins predicted from the VfEDL genes are cytoplasmic, similar to AtEDS1 (Falk et al. 1999).
Multiple sequence alignment of the deduced proteins from three VfEDL genes with Arabidopsis and Vitis EDS1 proteins was conducted using ClustalW to analyze the sequence characteristics. The G-X-S-X-G motif, which is highly conserved, is found in may lipases and esterases. This motif contains an active site residue of serine in the serine hydrolases family genes (Baudoin et al. 1997; Bezier et al. 2002; Reina et al. 2007; Lee et al. 2010). The L-family amino acid sequences contain the signature sequences of [LIV]-X[LIVFY]-[LIVMST]-G-[HYWV]-S-X-G-[GSTAC] around the active site serine that flanks a more commonly occurring G-X-S-X-G motif in the $\alpha / \beta$ hydrolase fold, and EDS1 conforms to the L family amino acid signature (Falk et al. 1999). Chong et al. (2007) showed that EDS1 sequences from Arabidopsis thaliana, Vitis vinifera, Solanum tuberosum, S. lycopersicum, Nicotiana tabacum and Oryza sativa contained the L-family/class 3 lipase consensus sequence, three lipase catalytic triads, a serine (S), an aspartate (D) and a histidine $(\mathrm{H})$, as well as the EDS1 and PAD4 (EP) conserved domain, which is well conserved among species. Wagner et al. (2013) also reported that plant EDS1 protein contained the consensus sequence of G-X-S-X-G and catalytic triads, a serine situated in the conserved G-X-S-X-G, an aspartic acid and a histidine by aligning sixteen plant EDS1 proteins. The alignment results showed that all proteins predicted from VfEDL genes contained the L-family lipase like domain (class 3 lipase domain) and also exhibited a potential lipase catalytic triad, aspartic acid, histidine and serine in the conserved G-X-S-X-G. The residues of the catalytic triad, which are essential for the activity of the hormone sensitive lipase in humans (Osterlund et al. 1996), were dispersed in primary amino acid sequences, but came together in the tertiary structure (Fig. 1 and 2). Sequence analysis revealed 


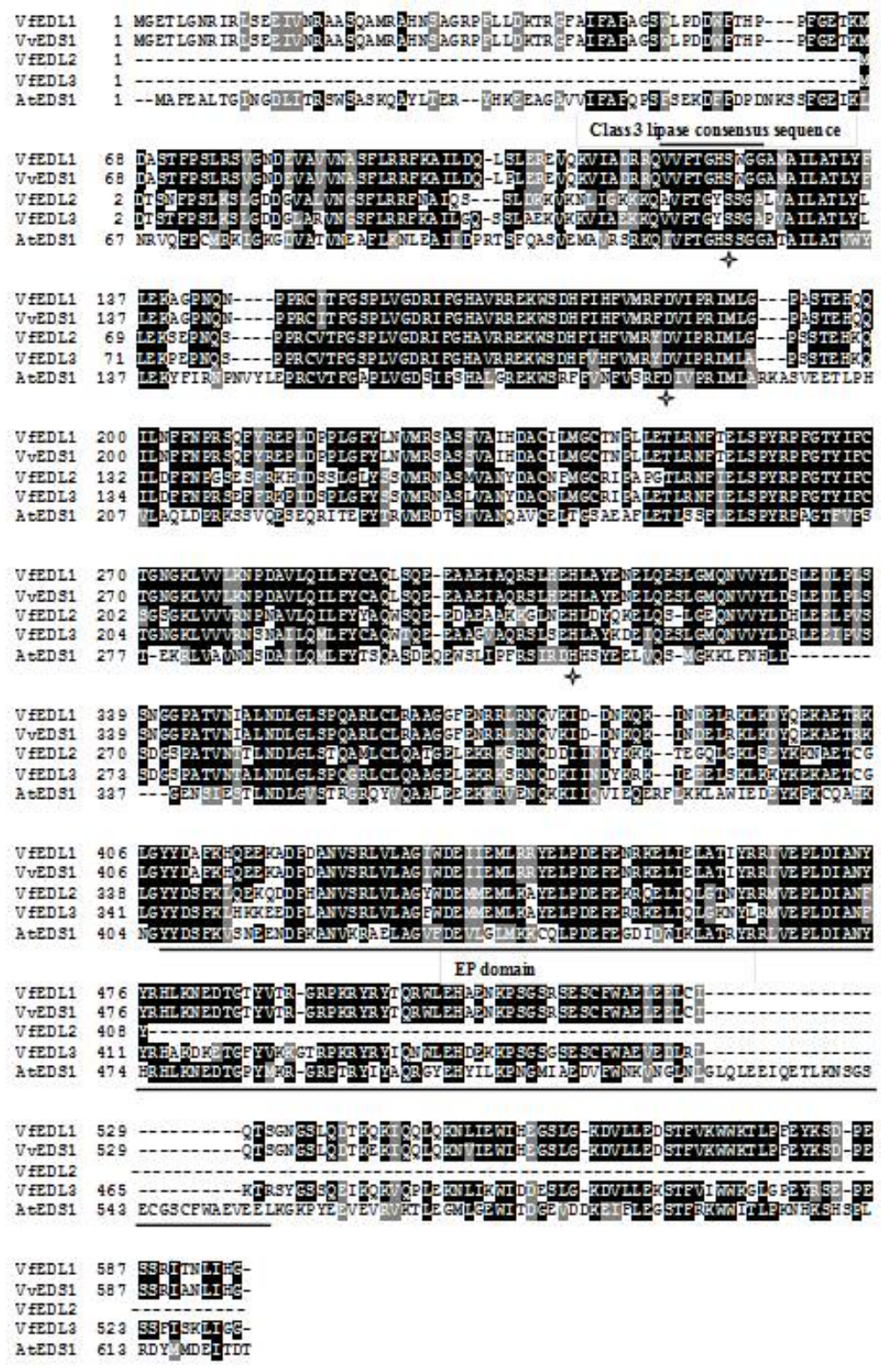

Fig. 1 Multiple alignment of three predicted proteins from the VfEDL gene and two other EDS1 proteins. The class 3 lipase consensus sequence is indicated by the bar above the motifs, the EP domain is shown by the bar under the domain, and asterisks indicate the positions of the catalytic triad inferred from AtEDS1 protein

that the predicted proteins from the EDL genes of $V$. flexuosa correspond to the characteristics of the EDS1 protein.

\section{Amino acid sequence comparison}

All protein sequences predicted from $V$. flexuosa were compared against themselves and Arabidopsis EDS1 protein (AtEDS1) using BLASTP (http://blast.ncbi.nlm.nih.gov/Blast. cgi) (Table 4). The results showed that VfEDL1, VfEDL2 and VfEDL3 were $43 \%, 41 \%$ and $42 \%$ identical to AtEDS1, respectively. The predicted amino acid sequences from
VfEDL genes showed $68 \%$ to $82 \%$ identity among themselves, with the highest similarity (82\%) observed between VfEDl2 and VfEDL3. Taken together, these findings indicated that VfED2 and VfEDL3 are duplicated genes according to Kong et al. (2013). A phylogenetic tree from 14 protein sequences related to EDS1 from dicots and monocots including three VfEDL proteins and two PAD4 proteins as the outgroup was constructed to show the genetic relationships among plant EDLs by the neighbor joining method using MEGA6 (Fig. 3).

EDS1 and PAD4 proteins are closely related in structure, both containing the $\mathrm{N}$-terminal lipase and C-terminal EP 


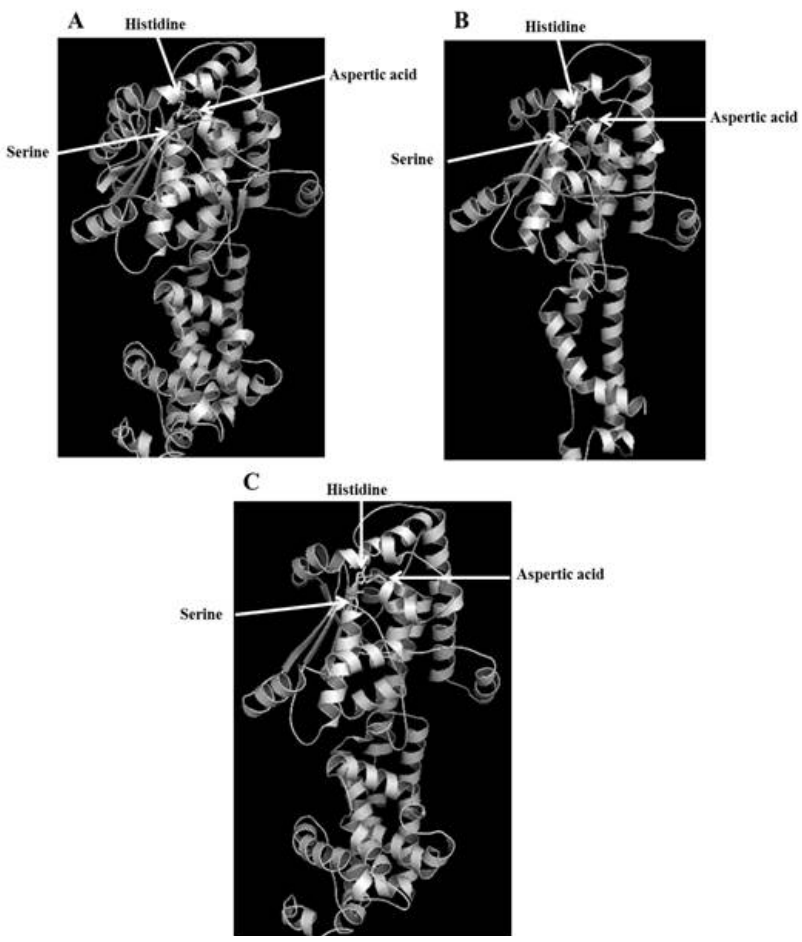

Fig. 2 Tertiary structure of VfEDL proteins: a) VfEDL1, b) VfEDL2 and c) VfEDL3 created by PyMOL. Sticks indicate conserved catalytic triads

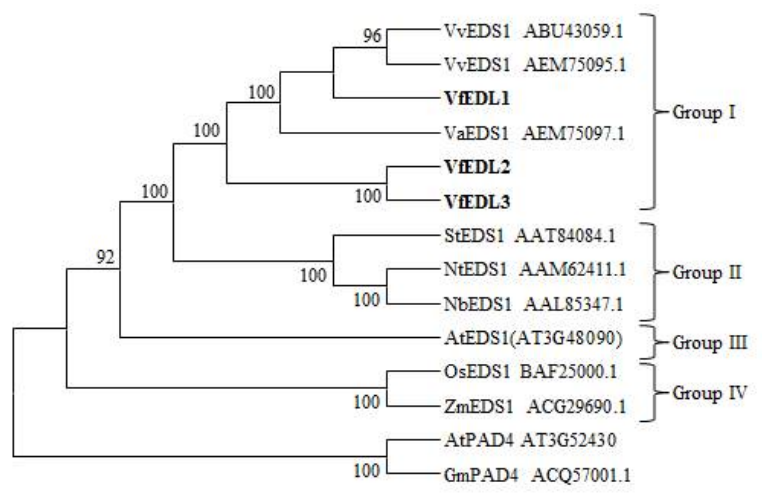

Fig. 3 Phylogenetic tree of predicted proteins from the VfEDL genes with other EDS1-like proteins. The unrooted tree was generated using the MEGA 6.0 software and the neighbor-joining method. Bootstrap values (above 70\%) from 1000 replicates are indicated at each node

domains (Wiermer et al., 2005), as well as in their function (Wagner et al. 2013). The genes were subdivided into four groups (group I-IV), excluding the out-group. In the tree, AtPAD4 and GmPAD4 were grouped as an out-group, and the VfEDL proteins were more closely related to EDS1 than PAD4. VfEDL proteins were clustered into the same group with Vitis EDS1 proteins and diverged from other proteins. Therefore, clustering EDLs in the phylogenic tree showed that EDS1 related proteins of Vitis are novel compared to other plant proteins. These results are consistent with those of a previous report that showed Vitis EDS1 proteins were grouped together in a phylogenetic tree and diverged from other plant proteins (Gao et al. 2010). The predicted amino acid sequences from the three loci of the VfEDL gene showed a high level of similarity with protein sequences of other plant species in a homology study of VfEDL genes by BLAST searches of the NCBI database. All VfEDL proteins were highly homologous with the protein sequences that originated from the Vitis genus, with identities of greater than $68 \%$ and $\mathrm{E}$ values of 0.0 , indicating their relatively conserved evolutionary relationship at the protein level (Table 5).

Expression analysis of VfEDL genes

Expression analysis of VfEDL genes against pathogen infections was performed by quantitative real-time PCR using gene specific primers based on nucleotide sequence alignment. The expression levels of tested genes in grapevine leaves infected with pathogens were examined based on comparison to uninoculated control samples. The expression levels of three VfEDL genes against $E$. ampelina pathogens are shown in Fig. 4a. VfEDL1 showed downregulated expression at all time points, while VfEDL2 and VfEDL3 were upregulated at $1 \mathrm{hpi}$ and downregulated during infection with $E$. ampelina. The highest expression of $V f E D L 3$ was observed at $1 \mathrm{hpi}$, which was upregulated 2.6 fold relative to the control. The responses of VfEDL genes to $R$. vitis infection are presented in Fig. $4 \mathrm{~b}$. All genes showed upregulated expression at $1 \mathrm{hpi}$ against $R$. vitis. Among them, VfEDL1 and VfEDL3 showed a rapid decrease in expression after 1 hpi and VfEDL3 showed upregulation for up to 24 hpi. The highest expression of VfEDL2 was 2.5 fold greater than that of the control at 1 hpi following $R$. vitis infection.

Table 4 Percent identities of the amino acid sequences among VfEDLs and AtEDS1

\begin{tabular}{ccccc}
\hline & VfEDL1 & VfEDL2 & VfEDL3 & AtEDS1 \\
\hline VfEDL1 & - & 68 & 71 & 43 \\
VfEDL2 & 68 & - & 82 & 41 \\
VfEDL3 & 71 & 82 & - & 42 \\
AtEDS1 & 43 & 41 & 42 & - \\
\hline
\end{tabular}


Table 5 Homology analysis of three predicted proteins from the VfEDL gene of $V$. flexuosa

\begin{tabular}{ccccccc}
\hline Protein & $\begin{array}{c}\text { Top matched } \\
\text { clones }\end{array}$ & $\begin{array}{c}\text { Top homologous } \\
\text { species }\end{array}$ & Identity (\%) & Query cover (\%) & E value & References \\
\hline VfEDL1 & ABU43059.1 & Vitis vinifera & 99 & 100 & 0.0 & Chong et al. (2008) \\
VfEDL2 & AEM75095.1 & Vitis vinifera & 68 & 100 & 0.0 & Gao et al. (2010) \\
VfEDL3 & AEM75097.1 & Vitis aestivalis & 71 & 100 & 0.0 & Gao et al. (2010) \\
\hline
\end{tabular}

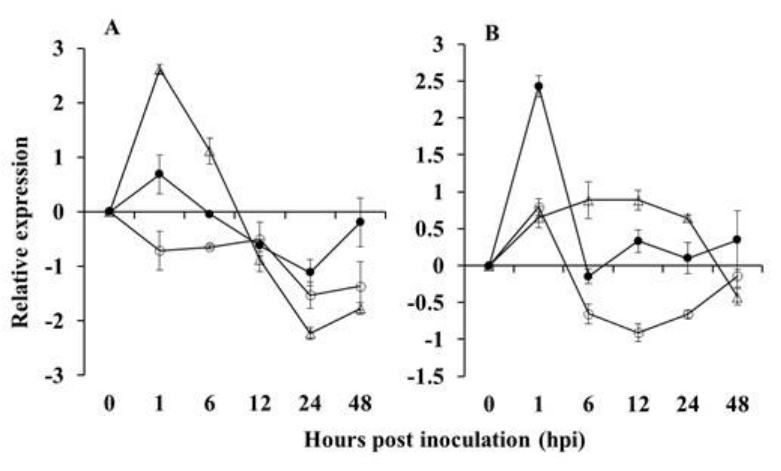

Fig. 4 Expression pattern of three EDL genes of Vitis flexuosa against $E$. ampellina (a) and $R$. vitis (b). VfEDL1 ( $\bullet)$, VfEDL2 (•) and $\operatorname{VfEDL3}(t)$. The error bars represent the standard error of the means of three independent replicates

EDS1 is an essential signaling component for resistance mediated by a large subclass of $\mathrm{R}$ genes denoted by the Toll interleukin 1 receptor-nucleotide binding site-leucine rich repeat (TIR-NBS-LRR) in Arabidopsis, which is downstream from R gene function (Glazebrook 2001; Wagner et al. 2013). EDS1 is also essential to hypersensitive cell death and basal resistance against bacterial, fungal and oomycete pathogens (Parker et al. 1996; Aarts et al. 1998; Falk et al. 1999; Jirage et al. 1999; Xiao et al. 2005; Oridi \& Bouarab 2007; Sing and Shah 2012). EDS1 functions in plant innate immunity with its partners, $S A G 101$ and PAD4 (Sing and Shah 2012; Wagner et al. 2013). EDS1 encodes the protein with homology to eukaryotic lipases and bears conserved lipase catalytic triads made up of an active site serine surrounded by the conserved consensus sequence G-X-S-X-G, an aspartic acid and a histidine (Falk et al. 1999; Wagner et al. 2013). In the present study, the molecular structure was analyzed to detect common characteristics in three VfEDL transcripts based on their predicted amino acid sequences in $V$. flexuosa. All tested VfEDL proteins contained the L-family lipase like domain (class 3 lipase domain) and exhibited a potential lipase catalytic triad, aspartic acid, histidine and serine in the conserved G-X-S-X-G. The residues of the catalytic triad were dispersed in primary amino acid sequences, but came together in the tertiary structure (Fig. 1 and Fig. 2), which are characteristic features of EDS1 like proteins. Phylogenetic analysis also showed that all of these proteins grouped with EDS1 proteins of Vitis (Fig. 3).

Defense responses against most pathogens are generally mediated by initiating signal pathways of disease resistance (R) genes in plants. In this pathway, signaling molecules are very important for receiving and transducing external and internal stimuli through signaling cascades to elicit appropriate cellular responses. To date, several signaling genes including EDS1, NDR1, PAD4, SID1, EDS5, SID2, EDS16, NPR1 and NIM1 required for the R gene specified resistance and signaling pathway have been discovered in Arabidopsis (Cao et al. 1994; Century et al. 1995; Delaney et al. 1995; Glazebrook et al. 1997; Rogers and Ausbel 1997; Aarts et al. 1998; Zhou et al. 1998; Falk et al. 1999; Nawrath and Metraux 1999; Rusterucci et al. 2001). Falk et al. (1999) reported that Arabidopsis EDS1 transcript was increased during infection with the bacterial pathogen Pseudomonas syringae, but its transcript was undetectable in its mutant plant. It has been reported that GmEDSla, GmEDSIb and GmPAD4 were induced to high levels in soybean at 2 days post inoculation (dpi) against the bacterial pathogen Pseudomonas syringae pv. glycinea (Psg) (Wang et al. 2014). They also showed decreased expression of these genes after silencing them. Moreover, GmEDSla, GmEDSlb and GmPAD4 decreased production of salicylic acid (SA) relative to control plants during Phytophthora sojae infection when these genes were silenced. These silenced plants also showed enhanced susceptibility to the bacterial pathogen $P$. syringae pv. glycinea, fungal pathogen $P$. sojae and soybean mosaic virus (SMV). Oridi and Bouarab (2007) reported that the expression levels of two plant signaling genes required for hypersensitive response dependent resistance, EDS1 and SGT1, were increased in Nicotiana benthamiana during Botrytis cinerea infection. Interestingly, they showed that these two signaling molecules are required for the disease caused by $B$. cinerea by silencing these genes when the necrotic disease was significantly reduced on leaves in silenced plants compared to control plants, and that EDS1 and SGT1 transcript accumulation was reduced in silenced plants. Gao et al. (2010) reported that there were no EDS1-like genes that were significantly upregulated by the grapevine powdery mildew pathogen 
Erysiphe necator in both resistant 'Norton' of $V$. aestivalis and susceptible 'Cabernet Sauvignon' of $V$. vinifera. Although transcript level was not significantly higher in treated samples than control samples, VaEDSI complemented Arabidopsis eds 1 mutants by reducing bacterial growth relative to eds 1 mutant during inoculation of Pseudomonas syringae pv. tomato strain DC3000 containing avrRps4.

In this study, we attempted to investigate the change of transcript levels of three VfEDL genes in response to infection with pathogenic fungi and bacteria in grapevines. In the expression study, all three VfEDL genes were upregulated at 1 hpi against bacterial pathogen $R$. vitis and two genes, VfEDL2 and VfEDL3, also showed upregulation at $1 \mathrm{hpi}$ against fungal pathogen E. ampelina, after which all of them showed reduction in their expressions. This expression pattern was similar to the previous reports about expression pattern of EDS1 genes (Oridi and Bouarab 2007; Gao et al. 2010; Wang et al. 2014). VfEDL1 showed down regulated expression at all time points against $E$. ampelina, but its expression was upregulated against $R$. vitis infection at early time points, suggesting that the VfEDL1 gene functions in diverse response processes against bacterial and fungal pathogens. Moreover, they exhibited different expression patterns in response to pathogen infections at various times, indicating that VfEDL plays a role in defense signaling pathways against pathogen infection in grapevines.

Signaling molecules play very important roles in defense mechanisms against pathogens by receiving and transducing external and internal stimuli in plants. EDS1-like genes are important signaling molecules in plants. In this study, we attempted to identify and characterize three transcripts of the VfEDL gene that showed various expression levels in the transcriptome of grapevines inoculated with $E$. ampelina. The molecular structures were analyzed to detect characteristics features in three EDS1-like genes. In addition, a homology comparison study was performed using NCBI BLAST searches and phylogenetic analysis based on their predicted amino acid sequences in $V$. flexuosa. Structural analysis and a comparison study confirmed that the tested genes are EDS1-like genes. Additionally, the expression pattern of VfEDL transcripts investigated by real-time PCR using gene specific primers showed that all genes tested in this study showed responses with different patterns against each tested pathogen, indicating that these genes may be involved in resistance responses against different pathogens in grapevines. The results presented herein provide valuable information to help unravel the complex signaling molecular mechanisms of resistance response to diseases in grapevines.

\section{Acknowledgement}

This work was supported by Grant no. PJ011939 from the Agricultural R\&D Project, Rural Development Administration, Republic of Korea.

\section{References}

Aarts N, Metz M, Holub E, Staskawicz B, Daniels M, Parker J (1998) Different requirements for $E D S 1$ and $N D R 1$ by disease resistance genes define at least two $R$ gene-mediated signaling pathways in Arabidopsis. Proc Natl Acad Sci USA 95: 10306-10311

Ahn S, Kim S, Jo S, Yun H (2014) De novo transcriptome analysis of Vitis flexuosa grapevine inoculated with Elsinoe ampelina. Plant Genet Resour-Charact Util 12:S130-S133

Ahn S, Kim S, Kim S, Yun H (2012) Differential expression screening of defense related genes in Vitis flexuosa grapevine against Elsinoe ampelina and Rhizobium vitis. Korean J Intl Agri 24:470-476

Baudouin E, Charpenteau M, Roby D, Macro Y, Ranjeva R, Ranty B (1997) Functional expression of a tobacco gene related to the serine hydrolase family esterase activity towards shortchain dinitrophenyl axcylesters. Eur. J. Biochem 248:700-706

Bezier A, Lamber B, Baillieul F (2002) Cloning of a grapevine Botrytis-responsive gene that has homology to the tobacco hypersensitivity-related hsr203J. J Exp Bot 53:2279-2280

Cao H, Bowling S, Gordon S, Dong X (1994) Characterization of an Arabidopsis mutant that is nonresponsive to inducers of systemic acquired resistance. Plant Cell 6:1583-1592

Century K, Holub E, Staskawicz B (1995) NDR1, a locus of Arabidopsis thaliana that is required for disease resistance to both a bacterial and fungal pathogen. Proc Natl Acad Sci USA 92:6597-6601

Chang S, Puryear J, Cairney J (1993) A simple and efficient method for isolating RNA from pine trees. Plant Mol Biol 11: $113-116$

Chong J, Le Henanff G, Bertsch C, Walter B (2007) Identification, expression analysis and characterization of defense and signaling genes in Vitis vinifera. Plant Physiol Biochem 46: $469-481$

Dangl J, Jones J (2001) Plant pathogens and integrated defense responses to infection. Nature 411:826-833

Delaney T, Friedrich L, Ryals J (1995) Arabidopsis signal transduction mutant defective in chemically and biologically induced disease resistance. Proc Natle Acad Sci USA 92: 6602-6606

Eastwell K, Sholberg P, Sayler R (2006) Characterizing potential bacterial biocontrol agents for suppression of Rhizobium vitis, causal agent of crown gall disease in grapevines. Crop Prot 25: 1191-1200

Eibach R, Diehl H, Alleweldt G (1989) Untersuchungen zur vererbung von resistenzeigenschaften bei reben gegen Oidium 
tuckeri, Plasmopara viticola and Botrytis cinerea. Vitis 28: 209-228

Falk A, Feys B, Frost L, Jones J, Daniels M Parker J (1999) EDS1, an essential component of R gene-mediated diseases resistance in Arabidopsis has homology to eukaryotic lipases. Proc Natl Acad Sci USA 96:3292-3297

Gao F, Shu X, Ali M, Howard S, Li N, Winterhagen P, Qiu W, Gassmann W(2010) A functional EDS1 ortholog is differentially regulated in powdery mildew resistant and susceptible grapevines and complements an Arabidopsis eds 1 mutant. Planta 231:1037-1047

Garcia A, Blanvillain-Baufume S, Huibers R, Wiermer M, Li G, Gobbato E, Rietz S, Parker J (2010) Balance nuclear and cytoplasmic activities of EDS1 are required for a complete plant innate immune response. PLos Pathog 6:e1000970

Gasteiger E, Gattiker A, Hoogland C, Ivanyi I, Appel R, Bairoch A (2003) ExPASy: the proteomics server for in-depth protein knowledge and analysis. Nucleic Acids Res 31:3784-3788

Geourjon C, Deleage G(1995) SOPMA: significant improvements in protein secondary structure prediction by consensus prediction from multiple alignments. Appl Biosci 11:681-684

Glazebrook J (2001) Genes controlling expression of defense responses in Arabidopsis. Curr Opin Plant Biol 4:301-308

Glazebrook J, Zook M, Mert F, Kagan I, Rogers E, Crute I, Holub E, Hammerschmidt R, Ausbel F (1997) Phytolexin-deficient mutants of Arabidopsis reveal that $P A D 4$ encodes a regulatory factor and that four $P A D$ genes contribute to downy mildew resistance. Genetics 146:381-392

Guruprasad K, Reddy B, Pandit M (1990) Correlation between stability of a protein and its dipeptide composition: a novel approach for predicting in vivo stability of a protein from its primary sequence. Protein Eng 4:155-161

Hammond-Kosack K, Jones J (1996) Resistance gene-dependent plant defense responses. Plant Cell 8:1773-1791

Heidrich K, Wirthmueller L, Tasset C, Pouzet C, Deslandes L, Parker J (2011) Arabidopsis EDS1 connects pathogen effector recognition to cell compartment-specific immune response. Science 334:1401-1404

Jirage D, Tootle T, Reubert T, Frost L, Feyes B, Parker J, Ausubel F, Glazebrook J (1999) Arabidopsis thaliana PAD4 encodes a lipase-like gene that is important for salicylic acid signaling. Proc Natl Acad Sci USA 96:13583-13588

Joshi R, Nayak S (2011) Functional characterization and signal transduction ability of nucleotide-binding site-leucine-rich repeat resistance genes in plants. Genet Mol Res 10:2637-2652

Kong X, Lv W, Jiang S, Zhang D, Cai G, Pan J, Li D (2013) Genome-wide identification and expression analysis of calcium-dependent protein kinase in maize. BMC Genomics 14:433

Kono A, Nakaune R, Yamada M, Nakano M, Mitani N, Ueno T (2009) Effect of culture conditions on conidia formation by Elsinoe ampelina, the causal organism of grapevine anthracnose. Plant Dis 93:481-484

Kortekamp A, Welter L, Vogt S, Knoll A, Schwander F, Töpfer R, Zyprian E (2008) Identification, isolation and characterization of a CC-NBS-LRR candidate disease resistance gene family in grapevine. Mol Breeding 22:421-432

Lee G, Chepyshko H, Chen H, Chu C, Chou Y, Akoh CC, Shaw J (2010) Genes and biochemical characterization of the three novel chlorophyllase isozymes from Brassica oleracea. J Agr Food Chem 58:8651-8657

Letunic I, Doerks T, Bork P (2009) SMART 6: Recent updates and new developments. Nucleic Acids Res 37: D229-D232 (database issue)

Liu J, Liu X, Dai L, Wang G (2007) Recent progress in elucidating the structure, function and evolution of disease resistance genes in plants. J Genet Genomics 34:765-776

Meyers B, Dickerman A, Michelmore R, Sivaramakrishnan S, Sobral B, Young N (1999) Plant disease resistance genes encode members of an ancient and diverse protein family with in the nucleotide-binding superfamily. Plant J 20:317-332

Nawrath C, Metraux J (1999) Salicylic acid induction deficient mutants of Arabidopsis expess $P R-2$ and $P R-5$ and accumulate high levels of camalexin after pathogen inoculation. Plant Cell 11:1393-1404

Oirdi M, Bouarab K (2007) Plant signalling components EDS1 and $S G T 1$ enhance disease caused by the necrotrophic pathogen Botrytis cinerea. New Phytol 175:131-139

Osterlund T, Danielsson B, Degerman E, Contreras JE, Edgren G, Davis RC, Schotz MC, Holm C (1996) Domain structure analysis of recombinant hormone sensitive lipase. Biochem $\mathrm{J}$ 319:411-420

Pan Q, Wendel J, Fluhr R (2000) Divergent evolution of plant NBS-LRR resistance gene homologues in dicot and cereal genomes. J Mol Evol 50:203-213

Parker J, Holub E, Frost L, Falk A, Gunn N, Daniels M (1996) Characterization of eds 1, a mutation in Arabidopsis suppressing resistance to Peronospora parasitica specified by several different RPP genes. Plant Cell 8:2033-2046

Reina J, Guerrero C, Heredia A (2007) Isolation, characterization, and localization of AgaSGNH cDNA: a new SGNH-motif plant hydrolase specific to Agave americana L. leaf epidermis. J Exp Bot 58:2717-2731

Rogers E, Ausbel F (1997) Arabidopsis enhanced disease susceptibility mutants exhibit enhanced susceptibility to several bacterial pathogens and alterations in $P R-1$ gene expression. Plant Cell 9:305-316

Rusterucci C, Aviv D, Holt B, Dangl J, Parker J (2001) The disease resistance signaling components EDS1 and PAD4 are essential regulators of the cell death pathway controlled by LSDI in Arabidopsis. Plant Cell 13:2211-2224

Singh I, Shah K (2012) In silico study of interaction between rice proteins enhanced disease susceptibility 1 and phytoalexin deficient 4, the regulators of salicylic acid signalling pathway. J Biosci 37:563-571

Staskawicz B, Ausubel F, Baker B, Ellis J, Jones J (1995) Molecular genetics of plant disease resistance. Science 268:661-667

Taler D, Galperin M, Benjamin I, Cohen Y, Kenigsbuch D (2004) Plant R genes that encode photorespiratory enzyme confer resistance against disease. Plant Cell 16:172-184 
Wagner S, Stuttmann J, Rietz S, Guerois R, Brunstein E, Bautor J, Niefind K, Parker JE (2013) Structural basis for signaling by exclusive EDS1 Heteromeric complexes with SAG101 or PAD4 in plant innate Immunity. Cell Host Microbe 14: 619-630

Wang J, Shine M, Gao Q, Navarre D, Jiang W, Liu C, Chen Q, Hu G, Kachroo A (2014) Enhanced disease susceptibilityl mediates pathogen resistance and virulence function of a bacterial effector in soybean. Plant Physiol 165:1269-1284

Wang Q, Zhang Y, Gao M, Jiao C, Wang X (2011) Identification and expression analysis of a pathogen responsive $P R-1$ gene from Chinese wild Vitis quinquangularis. Afr J Biotechnol 10:17062-17069
Wiermer M, Feys B, Parker J (2005) Plant immunity: the EDS1 regulatory node. Curr Opin Plant Biol 8:383-389

Xiao S, Calis O, Patrick E, Zhang G, Charoenwattana P, Muskett P, Parker JE, Turner JG (2005) The atypical resistance gene, RPW8, recruits components of basal defence for powdery mildew resistance in Arabidopsis. Plant J 42:95-110

Yun H, Park K, Roh J, Choi Y, Jeong S (2007) Developing a screening system for resistance to anthracnose in grapevines using culture filtrates from Elsinoe ampelina. J Hortic Sci Biotech 82:360-364

Zhou N, Tootle T, Tsui F, Klessig D, Glazebrook J (1998) PAD4 functions upstream from salicylic acid to control defense responses in Arabidopsis. Plant Cell 10:1021-1030 